\title{
Desafíos de la educación para la paz hacia la construcción de una cultura de paz
}

\section{Peace Education Challenges towards the Creation of a Culture of Peace}

\author{
Evelyn Cerdas-Agüero ${ }^{1}$ \\ Universidad Nacional \\ Instituto de Estudios Latinoamericanos \\ Heredia, Costa Rica \\ evelyncer@yahoo.com
}

\begin{abstract}
Recibido 19 de mayo de 2014 • Corregido 19 de febrero de 2015 • Aceptado 27 de abril de 2015
\end{abstract}
\begin{abstract}
Resumen. El presente trabajo aborda el tema de la educación para la paz y los desafíos que esta enfrenta, como lo son las manifestaciones de la violencia, para construir una cultura de paz. El objetivo es generar una reflexión acerca de los desafíos a los que se enfrenta la educación para la paz dirigida a la construcción de una cultura de paz en América Latina. Se plantea la educación para la paz como un proceso pedagógico que posibilita espacios de aprendizaje para desaprender la violencia y vivenciar la paz en las relaciones humanas. El trabajo permite concluir que las diversas manifestaciones de la violencia: estructural, directa y cultural, que afectan a la niñez, a las mujeres y a la juventud de la región latinoamericana condicionan la realización de sus derechos humanos y la construcción de una cultura de paz. Por lo tanto, se hace necesario un proceso de transformación, inicialmente a nivel individual, para renovar la esperanza, reconocer la autonomía, construir para la vida, pensar en la ternura y ser personas solidarias.
\end{abstract}

Palabras claves. Educación para la paz, América Latina, violencia, paz, cultura de paz.

Abstract. These paper deals with peace education and the recognition of violence as a main problem towards the process of creating a culture of peace. The purpose of this essay is to generate a reflection about challenges -such as violence, faced by peace education in order to contribute to a process to create a culture of peace. It suggests peace education as a pedagogical process for learning how not to learn and practice violence and to practice how to live in peace in any kind of human relationship. This paper concludes that violence expressions -either structural, direct or cultural, that has affected children, women and young people in Latin America determine the achievement of their human rights and the creation of a Culture of Peace. Therefore, a transformation process becomes necessary -initially at individual level, in order to renew hope, recognize autonomy, construct life, think about the tenderness, and be solidary people.

Keywords. Education for peace, Latin America, violence, peace, culture of peace.

${ }^{1}$ Doctoranda en Educación de la Universidad Estatal a Distancia (UNED), Costa Rica. Máster en Derechos Humanos y Educación para la Paz por la Universidad Nacional (UNA), Costa Rica. Coordinadora del Proyecto Aula Activa: Juegos Cooperativos para la Educación para la Paz en el Instituto de Estudios Latinoamericanos (IDELA), Universidad Nacional. Directora de la Revista Latinoamericana de Derechos Humanos del IDELA, Universidad Nacional. 
doi: http://dx.doi.org/10.15359/ree.19-2.9

URL: http://www.una.ac.cr/educare

CORREO: educare@una.cr

El objetivo de este trabajo se dirige a reflexionar acerca de los desafíos con respecto a la violencia a los que se enfrenta la educación para la paz dirigida a la construcción de una cultura de paz en América Latina.

La educación para la paz se constituye como una estrategia, un desafío y un proceso educativo basada en el reconocimiento, el respeto y la vivencia de los derechos humanos, así como el respeto a la dignidad de las personas, dirigida a la construcción de la cultura de paz en la región latinoamericana. La asumimos como una educación que incide desde diversos espacios sociales y en estos, en las estructuras, en las diversas formas de pensar y de asumir las realidades sociales.

La educación para la paz es un proceso trascendental para la construcción de la cultura de paz; visualizamos esta como un proceso lento y complejo; pero realista, influenciado por una serie de factores sociales que se deben enfrentar y transformar; sobre todo, implica un proceso de cambio de mentalidad y de actitudes individuales y colectivas para el empoderamiento y la acción.

El trabajo se construye por medio del abordaje de algunos conceptos y principios clave con respecto a lo que se entiende por cultura de paz y educación para la paz, así en su desarrollo se incorporan otros componentes teóricos relacionados. Además, se muestran algunos ejemplos de la violencia presente en la región latinoamericana. Se enfoca en poblaciones que han sido vulnerabilizadas como las mujeres, los niños, las niñas y las personas jóvenes. Visualiza las manifestaciones de la violencia estructural, cultural y directa como retos importantes que enfrentar. Asimismo, se ejemplifican algunas prácticas que se llevan a cabo para la promoción de una cultura de paz y se concluye con algunas reflexiones con respecto a la necesidad de cambios subjetivos de las personas en una sociedad que busca construir la paz.

\section{Cultura de paz y educación para la paz: Conceptos y principios clave}

Se entiende la cultura de paz como aquella que se caracteriza por actitudes, formas de conducta y de vida, y valores basados en el respeto a la vida, los derechos humanos, la promoción y la práctica de la no violencia, por medio de la educación, el diálogo, la cooperación, la igualdad de derechos y de oportunidades, la libertad, la justicia, la aceptación de las diferencias y la solidaridad (Asamblea General de Naciones Unidas, 1999).

La promoción y la construcción de esta se logran por medio de prácticas que fomenten la paz y el respecto a la dignidad humana entre todas las personas y los diversos grupos que conforman la sociedad. En estas prácticas, la persona es protagonista de su propia historia, sujeto y constructora del cambio. Este protagonismo se asume viviendo los principios de esta cultura, los 
doi: http://dx.doi.org/10.15359/ree.19-2.9

URL: http://www.una.ac.cr/educare

cuales, según el Manifiesto 2000 para una cultura de paz y no violencia (UNESCO, 1999), se refieren al respeto por la vida y dignidad de todas las personas; la práctica de la no violencia activa y el rechazo de todas las formas de violencia; el compartir con las demás personas; la lucha contra la exclusión, la injusticia y la opresión política y económica; respetar y defender la diversidad cultural; la búsqueda de la libertad de expresión; la práctica del diálogo; contribuir al desarrollo sostenible; propiciar la participación de las mujeres y redescubrir nuevas formas de solidaridad.

En este sentido, la paz se plantea como un valor esencial y un derecho humano: la ausencia o reducción de todo tipo de violencia; la transformación creativa y no violenta de los conflictos; la cooperación; la bondad verbal y física dirigida a las necesidades básicas de supervivencia, bienestar, libertad e identidad; la prevalencia de la libertad, la equidad, el diálogo, la integración, la solidaridad, la participación, la legitimación de la paz en los espacios simbólicos, la satisfacción de las necesidades humanas, la justicia social, y la potenciación de la vida (Galtung, 2003; Jiménez, 2011; Muñoz, 2004).

La paz es una vivencia; se vincula con las relaciones y las condiciones sociales; es una lucha contra las relaciones y condiciones basadas en la desigualdad, la exclusión y la violencia. La base de esta es el reconocimiento de la dignidad del ser humano, el reconocimiento y respeto de sus derechos y libertades fundamentales.

Así, la educación para la paz se refiere a una educación que"contribuya a generar procesos sociales basados en la confianza, la solidaridad y el respeto mutuo, facilite la solución pacífica de los conflictos y ayude a pensar de una forma nueva las relaciones humanas" (Declaración de Luarca [Asturias] sobre el derecho humano a la paz, 2008, artículo 2, p. 112).

De acuerdo con Aguilera, Cascón y Bastida (2000), esta educación posee una serie de características para su praxis, por medio de las cuales cuestiona procesos educativos, enfatiza en las tipologías de la violencia, busca el surgimiento de estructuras poco autoritarias, pretende que se refleje una coincidencia entre los fines y medios de la educación, busca la aprehensión de valores que estimulen al cambio social y personal; además, procura sensibilizar para la comprensión, el aprecio y la aceptación de las diferencias. Lo anterior se logra por medio de la educación como un proceso:

... educativo dinámico, continuo y permanente, fundamentado en los conceptos de paz positiva y en la perspectiva creativa del conflicto, como elementos significantes y definidores, y que a través de la aplicación de enfoques socioafectivos y problematizantes pretende desarrollar un nuevo tipo de cultura, la cultura de paz que ayude a las personas a desvelar críticamente la realidad para poder situarse en ella y actuar en consecuencia. (Jares, 1999, p. 124) 
doi: http://dx.doi.org/10.15359/ree.19-2.9

URL: http://www.una.ac.cr/educare

CORREO: educare@una.cr

Esta realidad de la cual habla Jares (1999) es en varias dimensiones: cada persona consigo misma y con las demás, con las interacciones y desde estas y las estructuras sociales, así como con el ambiente. Se trata de una realidad vivencial que se constituye en una praxis de transformación y liberación. Así, estamos planteando que la educación para la paz abarca más que la transferencia de información, implica trabajar en una lucha constante por los cambios en las estructuras sociales al reconocer que estos requieren de procesos que se enmarcan en diferentes contextos sociohistóricos y culturales, "no es una acción que termine en sí misma, sino que está proyectada para generar otras acciones, múltiples y en ámbitos también múltiples" (Bonifacio, 1997, citado por Beltrán, 2007, p. 40).

De esta forma, la educación para la paz constituye un proceso de aprendizaje en el cual el ser humano es agente de transformación, se centra en la persona al creer que tiene potencial y posee las capacidades que le permiten participar de forma autónoma, no violenta, decidida y activa en el desarrollo humano e incidir en la sociedad para promover y construir la paz.

Sin embargo, el reto primordial consiste, también, en que las personas se reconozcan a sí mismas como solidarias, autónomas, con dignidad y derechos para ejercerlos, reclamarlos y defenderlos; como sujetos que crean y transforman su propia historia. En este sentido, las acciones de las personas en un determinado entorno son acciones generadoras de una nueva realidad, de manera que el ser humano, por sus actitudes y actos, puede lograr un impacto en esta y crear una diferente de aquella que es violenta y opresora por una pacífica.

Lo anterior, porque la educación es un acto consciente, en el cual existe la necesidad de conocer qué modelo de personas y de sociedad queremos tener, construir y transformar; cuál es la cultura de paz que deseamos y basada en cuáles principios. Es, entonces, educar para una forma de vida que implique el cambio de actitudes y reestructuración de aquellas estructuras mentales aprendidas que no promueven la paz ni el respeto a la dignidad de las personas.

Se trata de una educación crítica y emancipadora, porque uno de sus objetivos es promover la autonomía y la afirmación personal, el empoderamiento ante las realidades injustas y excluyentes; comprende más que la transferencia de información, implica trabajar en una lucha constante por los cambios en las estructuras sociales basadas en la violencia estructural y la desigualdad. Esta acción es una lucha que deben llevar a cabo los pueblos latinoamericanos, la cual, según Freire (2005), no se manifiesta en una actitud pasiva de "quien cruza los brazos y espera" (p. 111), sino que se centra en una lucha que nace con la esperanza motivadora.

Esta lucha se lleva a cabo por medio de un proceso de lectura crítica de la realidad, sensibilización e identificación con esta. Velázquez (2001 citado por M. T. Pinheiro, 2006) explica que la educación para paz se visualiza como un proceso de constante concienciación de las personas y de la sociedad para "aprender a vivir juntos y con los otros (para desarrollar la comprensión del otro y la percepción de las formas de interdependencia respetando los valores 
doi: http://dx.doi.org/10.15359/ree.19-2.9

URL: http://www.una.ac.cr/educare

del pluralismo, comprensión mutua y paz)..." (Delors, 1996 citado por Monclús y Sabán, 1999, p. 102). Así, la educación para la paz también sensibiliza y dirige a pensar, visualizar y vivir de una nueva forma las relaciones humanas, en las cuales aprendamos a vivir junto a los demás individuos, con otras personas y para las otras, así como desarrollar las capacidades personales, ejercer las libertades, actuar con autonomía, asumir responsabilidades y crecer en la solidaridad, la esperanza y el amor humanos Así, la educación para la paz también sensibiliza y dirige a pensar, visualizar y vivir de una nueva forma las relaciones humanas, en las cuales aprendamos a vivir juntos (as), con y para los (as) otros (as), así como desarrollar las capacidades personales, ejercer las libertades, ser autónomos (as), asumir responsabilidades y crecer en la solidaridad, la esperanza y el amor humanos.

Además, promueve la praxis, porque la educación para la paz provee las herramientas a las personas para que generen estrategias, construyan y promuevan la cultura de paz desde el espacio local, puesto que "la educación a todos los niveles es uno de los medios fundamentales para edificar una cultura de paz ..." (Asamblea General de Naciones Unidas, 1999, Artículo 4) y para promover y defender los derechos humanos. Porque educar para la paz es, en sentido estricto, educar para los derechos humanos, pero no solo conocerlos, enseñarlos o aprenderlos, sino practicarlos en una lucha constante.

Por tanto, se establece un vínculo inequívoco entre la educación para la paz y la promoción, construcción y consolidación de una cultura de paz, por medio del reconocimiento, aprehensión y respeto de los derechos humanos, la aceptación de las diferencias, la no violencia, la justicia, la libertad y el diálogo, de forma que esta se interiorice individual y colectivamente, basada en relaciones pacíficas y armoniosas entre los seres humanos y cada quien consigo, en un reto constante por la transformación.

Sin embargo, estamos frente a una realidad social plasmada por injusticias, violencias, exclusión y discriminación, la cual el sujeto debe trascender. La violencia presente en las realidades sociales en América Latina es uno de los factores más complejos que nublan la realización de los derechos humanos y, por ende, la construcción de la cultura de paz. Esto se vincula con el planteamiento de Marx, citado por Gallardo (2011, 1.- Posicionamientos. párr. 4):

Los seres humanos hacen su propia historia, pero no la hacen a su libre arbitrio, en circunstancias elegidas por ellos mismos, sino en aquellas circunstancias con las que se encuentran directamente, que existen y les han sido legadas por el pasado.

La cuestión medular es, entonces, cómo cambiar esta historia legada, pasada y que puede ser un fantasma de condiciones poco favorables para el desarrollo humano y la calidad de vida. Algunos ejemplos de este panorama los veremos a continuación, especialmente aquellos que se relacionan con la violencia. 
doi: http://dx.doi.org/10.15359/ree.19-2.9

URL: http://www.una.ac.cr/educare

CORREO: educare@una.cr

\section{Un panorama general de la región latinoamericana: La violencia que nubla la realización de los Derechos Humanos}

La violencia se ha manifestado de diversas formas a lo largo de la historia de cambio y búsqueda de transformaciones en la región latinoamericana. América Latina ha evolucionado de una violencia política que caracterizaba, en su mayoría, la región entre las décadas de 1970 y 1980, a una violencia social ligada a factores estructurales como la pobreza, la desigualdad y la exclusión social. Estos factores de orden estructural se reflejan en los estudios que indican que América Latina es una de las regiones con las mayores desigualdades del mundo en la distribución del ingreso, "el $40 \%$ de la población más pobre recibe el $10 \%$ de los ingresos totales y el $20 \%$ de la población más acomodada recibe más del $60 \%$ de estos" (UNICEF, 2006, p. 18).

En este sentido, entendemos por violencia las "afrentas evitables a las necesidades humanas básicas, y más globalmente, contra la vida, rebajan el nivel real de satisfacción de las necesidades por debajo de lo que es potencialmente posible. Las amenazas de violencia son también violencia" (Galtung, 2003, p. 262). De acuerdo con esta definición, enfocamos la violencia como los actos y condiciones que privan las necesidades humanas, amenazan la vida de las personas, su integridad física y psicológica, su dignidad humana, limitan su desarrollo, su bienestar, sus libertades y la realización plena de sus derechos humanos.

En este aspecto, estamos hablando de diversas tipologías de violencia que interactúan; la directa, la estructural y la cultural. La violencia directa se concreta en espacios personales, sociales y mundiales; se caracteriza por ser intencionada, desplegada por acciones individuales o por personas dentro de colectividades (Galtung, 2003). Se ejerce contra la integridad física y psicológica; puede manifestarse como violencia física, sexual o verbal. La violencia estructural es aquella que se encuentra inserta en espacios personales, sociales, institucionales y mundiales (Galtung, 2003). Está presente en la injusticia social, la desigualdad, la inequidad, la pobreza, la exclusión y la marginación, lo que genera que muchas necesidades de las personas no sean satisfechas.

Por otro lado, la violencia cultural se refiere a aspectos de la cultura (simbólicos) que se utilizan para justificar o dar legitimidad a la violencia directa o estructural (Galtung, 2003), se manifiesta por medio del lenguaje, la religión, los símbolos, ideologías y artes. La justificación que genera esta violencia es lo que permite que los actos y consecuencias que reflejan los otros dos tipos de violencia sean aceptados por la sociedad o determinados grupos sociales; por esto opaca o encubre la realidad y las consecuencias de la violencia; así esta llega a visualizarse como normal, cargada de razón y como parte natural de la realidad. Esto genera que no se contrarreste de forma importante la violencia estructural y directa. 
doi: http://dx.doi.org/10.15359/ree.19-2.9

URL: http://www.una.ac.cr/educare

Las tres tipologías de la violencia están presentes y relacionadas en la realidad de América Latina. La existencia de violencia estructural como el patriarcado, la pobreza, la discriminación y la exclusión social en muchos casos genera violencia directa, como es la violencia contra las mujeres, los niños y las niñas, adolescentes y jóvenes. Esta violencia se justifica por pautas culturales, expresiones de la violencia cultural que legitiman el adultocentrismo, el patriarcado, el uso del cuerpo de las mujeres como mercancía, la competencia, el individualismo, etc.

En América Latina, el aumento de la desigualdad y la exclusión, así como la violación de los derechos humanos genera un panorama de inestabilidad en el que la violencia se manifiesta en sus diferentes formas y genera círculos de violencia, inseguridad, desconfianza y vulneración de derechos con gran complejidad. Afecta, en gran medida, a grupos que por diversas condiciones sociales, culturales y políticas se han considerado tradicionalmente como los más vulnerables, tales como la niñez, las mujeres y la juventud.

\section{Violencia contra los niños y las niñas}

Con respecto a la niñez, se puede hablar de diversas manifestaciones de la violencia como la violencia intrafamiliar, la violencia escolar y el trabajo infantil. Los porcentajes de violencia intrafamiliar contra niños y niñas en los países de América Latina varían entre un 33\% y un 93\% según el país (UNICEF, 2011). De acuerdo con el Informe Mundial de la Violencia contra los niños y las niñas (P. S. Pinheiro, 2006), se estima que en América Latina y el Caribe existe un aproximado de 11.3 y 25.5 millones de niños y niñas que anualmente presencian al menos algún tipo de violencia en el hogar. Esta violencia genera consecuencias como la expulsión de los niños y las niñas del hogar. Según un Informe del BID (citado por UNICEF, 2006), en la región latinoamericana existen aproximadamente 7 millones de niños, niñas y adolescentes que deambulan en las calles, situación vinculada con diversos factores como la deserción escolar, la explotación y el abuso sexual, entre otras.

En lo que se refiere a la violencia escolar, niños, niñas y adolescentes que han sido víctimas de acoso escolar o conocen estos hechos alcanzan entre un $50 \%$ y un $70 \%$ de la población estudiantil (UNICEF, 2011).

Aunado a esto, se encuentran las altas cifras del trabajo infantil, puesto que en América Latina y el Caribe alcanzan los 14.1 millones (del grupo de edad entre 5 y 17 años) de los cuales entre $5.6 \%$ y $6.5 \%$ están expuestos a condiciones peligrosas. Los datos de los niños y las niñas entre 5 y 14 años es de 110.566 (miles) en el 2008 (Oficina Internacional del Trabajo [OIT], 2010). El escenario del trabajo infantil muestra que en el caso del trabajo en condiciones peligrosas este atenta contra la integridad física de los niños y las niñas, pero de igual forma en otras condiciones este implica abandono de la escolarización, en muchos casos abandono del hogar, violencia física, sexual y psicológica, así como explotación sexual. 
doi: http://dx.doi.org/10.15359/ree.19-2.9

URL: http://www.una.ac.cr/educare

CORREO: educare@una.cr

La violencia contra niños y niñas está enmarcada en aspectos culturales en los que las relaciones de poder se manifiestan a través de relaciones de desigualdad mediadas por el adultocentrismo; estas justifican el uso del poder en menoscabo de sus derechos, porque el adultocentrismo somete a las niñas y a los niños a las disposiciones de las personas adultas y al abuso de poder que implica una posición de no sujetos y de subordinación.

Asimismo, se ve justificada por refuerzos sociales como la tolerancia por medio de la cual se aceptan las diferentes formas de violencia o se minimizan sus consecuencias, así como por factores culturales que la aprueban, por ejemplo, el castigo físico, las agresiones contra pares en defensa propia o los estereotipos, etc. Esta violencia invisibiliza a los niños y las niñas como personas con derechos, a la vez, genera una ocultación social que enfoca esta población como el futuro de la sociedad, pero están ausentes del mundo "de las personas adultas" como sujetosactores en el presente.

\section{La violencia contra las mujeres}

Una de las principales manifestaciones es la violencia expresada en diferentes formas como la sexual, física, verbal, psicológica, patrimonial y la falta de acceso a oportunidades. Esta se basa en las relaciones de poder desiguales en un sistema patriarcal que somete las mujeres; este es un sistema enmarcado en la violencia estructural, domina a las mujeres, le confiere el poder al género masculino en los diferentes espacios de la vida cotidiana. Es, además, una violencia cultural que se legitima con modelos culturales religiosos, artísticos y del lenguaje, a la vez que se manifiesta por medio de la violencia directa que afecta el cuerpo, la mente y el espíritu.

Una de las manifestaciones de la violencia contra la mujer se genera en el espacio familiar, violencia intrafamiliar, es en el espacio privado porque es menos explícita, menos juzgada y más silenciosa, es una violencia que parece estar invisible, pues es asumida con mayor naturalidad y absorbida por el espacio privado y por la cultura que la legitima.

En la región latinoamericana se evidencia que entre un $10 \%$ y un $36 \%$ de las mujeres, según el país, ha sido objeto de violencia física o sexual, sin considerar los datos de la violencia psicológica (UNICEF, 2006). América del Sur, el Caribe y Centroamérica figuran entre las regiones con más altos porcentajes de femicidios en el mundo y los países de El Salvador y Guatemala son los países de la región con las tasas más altas en América Latina (Geneva Declaration on Armed Violence and Development, 2011).

Es una violencia de género que permea los espacios y las relaciones sociales sin importar nacionalidad, edad, religión, posición social; es ejercida desde cualquier espacio social y con cualquier objeto material o simbólico que genere sufrimientos físicos, sexuales o psicológicos que interfiera con la calidad y proyecto de vida de las mujeres. 
doi: http://dx.doi.org/10.15359/ree.19-2.9

URL: http://www.una.ac.cr/educare

La violencia contra las mujeres las vulnerabiliza, les impide vivir dignamente la realización plena de sus derechos, así como acceder a diversas oportunidades sociales, culturales, económicas y políticas. Sin embargo, es necesario reconocer que muchas de las mujeres que sufren la violencia no siempre la visualizan como tal o no tienen la conciencia de la magnitud de sus consecuencias en su calidad de vida, su desarrollo, su proyecto de vida o a nivel intergeneracional, porque existe una serie de elementos culturales que la justifican como parte de la violencia cultural.

Lo anterior genera que no haya resistencia y se acepte la situación tal y como es, lo cual perpetúa esta violencia; este es uno de los elementos más complejos que enfrentar en la lucha contra esta forma de violencia: la existencia de supuestos que la hacen invisible, razonable o normal.

\section{Violencia juvenil}

Con respecto a la población de jóvenes, esta se ha tomado en muchos aspectos como un sector que genera criminalidad y violencia y no como el que la recibe; sin embargo, ambos aspectos se vinculan: la falta de oportunidades educativas, de empleo, de crecimiento personal, la expulsión y el bajo rendimiento escolar son factores importantes de violencia hacia esta población. Estos también conllevan falta de oportunidades económicas y sociales, y genera efectos de violencia hacia la sociedad. Aunado a ello, se suman entornos familiares y sociales plasmados de violencia, drogas, pobreza y exclusión por motivos de origen étnico y nacional, preferencias sexuales, color de piel, género, etc. Estos factores desempeñan roles importantes en los índices de violencia juvenil. De acuerdo con Buvinic (citado por UNICEF, 2006), otros elementos significativos son el consumo de drogas y alcohol, la disponibilidad de armas de fuego, el aprendizaje de la violencia como forma de resolver conflictos.

Uno de los fenómenos evidentes en América Latina es la presencia de pandillas de adolescentes y jóvenes en barrios caracterizados por la pobreza y la marginación social, los cuales se constituyen en sectores de la población sumergidos en una constante violencia. El Salvador y Colombia son los países de América Latina donde la violencia causada por las pandillas es mayor; pero también existen serios problemas en Brasil, Ecuador, México, Perú, Honduras y Guatemala (UNICEF, 2006).

La pertenencia a las pandillas conduce a una serie de factores de riesgo como la violencia intrafamiliar, la violencia en los centros escolares y en las comunidades, la falta de oportunidades de acceso a la educación, empleo y deportes, entre otros; sin embargo, diversas investigaciones coinciden en que "los comportamientos juveniles violentos son consecuencia de procesos estructurales vinculados a la persistencia de la pobreza y del desempleo" (Comisión Económica para América Latina y El caribe [CEPAL] y Naciones Unidas [NU], 2008, p. 173). 
doi: http://dx.doi.org/10.15359/ree.19-2.9

URL: http://www.una.ac.cr/educare

CORREO: educare@una.cr

Además, la violencia entre los sectores jóvenes está condicionada por factores de violencia estructural, que si bien no justifican sus actos, los condicionan y los generan en gran medida. Se sustenta en las diversas formas de exclusión social (económica, política y cultural): la falta y desigualdad de oportunidades; la falta de acceso al empleo y a la educación; la falta de espacios participativos; la desigualdad, la discriminación y la pobreza. El hecho de que muchos jóvenes no puedan realizar sus potencialidades y no tengan cubiertas sus necesidades puede generar incertidumbre e inseguridad y frustración, multiplicándose en otras manifestaciones de violencia como agresiones, delincuencia juvenil y generando, así, un círculo inacabable.

Las diversas manifestaciones de violencia mencionadas anteriormente y otras que afectan la región latinoamericana cercenan los derechos humanos, el desarrollo humano y la dignidad de las personas; generan inseguridad social, desesperanza, desconfianza y más violencia. Ante esta realidad, es necesario actuar, enfrentar la violencia como un desafío necesario de erradicar en la región como parte de la construcción de una cultura de paz.

Es clara la relación de interdependencia entre derechos humanos y estas manifestaciones de violencia, debido a que la violencia es un espacio favorable para la violación de los derechos humanos (Magendzo, 2008) y la educación para la paz se convierte en un instrumento para su prevención y reducción. No se puede hablar de una cultura de paz mientras tales situaciones injustas, dispares y transgresoras de la dignidad humana estén en constante evolución en América Latina y, sobre todo, con un orden globalizado de competencia, individualismo, consumismo, inequidad y poder en manos de pocos individuos o sectores.

\section{Algunos ejemplos en la región para la promoción y construcción de una cultura de paz}

Promover y construir la cultura de paz en la región latinoamericana en espacios permeados por la violencia ha sido un reto continuo. Con respecto a la violencia juvenil, la "mano dura" no ha generado resultados positivos, tampoco es la solución o la herramienta para su prevención Existen otras estrategias que pueden tener mejores resultados.

De acuerdo con la Organización Iberoamericana de Juventud (OIJ, 2011), de forma general, en la región se ha trabajado fomentando la participación y la ciudadanía en tres ámbitos: la participación política juvenil, el fortalecimiento de las organizaciones y los movimientos juveniles (educación no formal) y la formación ciudadana de jóvenes (educación formal). Además, se está trabajando en la promoción juvenil en espacios culturales como el deporte, grupos teatrales, grupos de música, ya sea de forma institucionalizada o menos formal. Esto se ha logrado, en gran medida, por la promoción de las casas de la cultura, casas de la juventud y clubes juveniles, entre otros. 
doi: http://dx.doi.org/10.15359/ree.19-2.9

URL: http://www.una.ac.cr/educare

En El Salvador, se está llevando a cabo una iniciativa desde el 2011 hasta el 2014, "Programa PROJÓVENES", dirigido a la prevención de la violencia de forma focalizada en espacios definidos, en algunos de los municipios considerados con altos índices de delincuencia y violencia. El programa se articula en varios componentes importantes para la prevención de la violencia como: el fortalecimiento de instituciones, desarrollo comunitario, formación laboral, recuperación de espacios públicos, asistencia técnica, promoción de materiales contra la violencia o su prevención (OIJ, 2011).

El fortalecimiento de las capacidades instituciones locales en la prevención de la violencia es importante porque visibiliza la problemática, sensibiliza para que los actores sean parte de las propuestas y encaminen sus proyectos para prevenir la violencia y enfocarse en factores que contribuyen a sus manifestaciones. Además, el trabajo en el desarrollo comunitario es trascendental porque trata de incorporar a todos los actores de la comunidad -desde las familias, hasta centros escolares, iglesias y grupos organizados-, para lograr una integración de grupos que identifiquen los factores de violencia y trabajen para una comunidad más pacífica.

La formación laboral busca incrementar oportunidades económicas y capacidades laborales para la juventud y sus familias, "es un sistema que incluye un diagnóstico sobre la demanda y la oferta laboral, capacitación y becas, dirigido a madres solteras, jóvenes en riesgo y jóvenes en conflicto con la ley. Además, integra el Programa de Emprendedurismo, en donde se les entrega capital semilla" (OIJ, 2011, p. 81). La recuperación de espacios públicos implica aquellos espacios para el deporte, el ocio y la recreación que deben adaptarse y aprovecharse para la realización de actividades deportivas, educativas y culturales para la participación de jóvenes y la prevención de la violencia.

Pareciera que el proyecto es muy técnico; sin embargo, su importancia en la construcción de una cultura de paz radica en la incorporación de actores comunitarios que se vinculen en el trabajo para prevenir la violencia, así como el fortalecimiento de capacidades laborales para tener mayores oportunidades de crecimiento económico. El trabajo con las municipalidades es también importante para llevar a cabo programas de prevención de la violencia, debido a que se circunscribe a un ámbito territorial delimitado, facilita la coordinación de distintas instancias y permite concertar compromisos y responsabilidades.

Lo anterior es trascendental, pues consiste en un esfuerzo integral que debe visualizar la violencia no solo en el nivel individual sino colectivo, caracterizado por complejidades estructurales. Jares (1999) lo plantea como la superación de la dicotomía entre el cambio personal y el cambio estructural, es decir, la necesidad de visualizar las realidades más próximas (micromedio) y las más lejanas (macromedio) y actuar sobre estas para así generar un efecto sobre el macromedio. De acuerdo con Jares (1999), en la educación para la paz es necesario enfatizar en la relación que existe entre el nivel macro y el micro, en tanto que "la microsituación 
doi: http://dx.doi.org/10.15359/ree.19-2.9

URL: http://www.una.ac.cr/educare

CORREO: educare@una.cr

es consecuencia en parte de la macrosituación" (p. 202); es decir, se podría pensar en las situaciones globales, pero actuar en lo local y desde ahí para transformar la realidad: ello puede generar grandes efectos positivos.

En México, La Dirección General de Educación por los Derechos Humanos de La Comisión de Derechos Humanos del Distrito Federal (CDHDF) lleva a cabo el programa "Escuela de formación, una alternativa a la violencia en la comunidad educativa". Consiste en una estrategia educativa en pro de la niñez dirigida a docentes y actores en la comunidad escolar. El programa imparte talleres, cursos y diplomados en los que se abordan temas como derechos humanos, derechos de la niñez, prevención del maltrato y abuso sexual infantil, explotación sexual comercial infantil, educación para la paz, resolución no violenta de conflictos, género y no discriminación, entre otros (Comisión de Derechos Humanos del Distrito Federal [CDHDF], 2011).

El programa sitúa la escuela como un espacio clave en la prevención de la violencia y en la promoción de una cultura de paz al proponer metodologías dialógico-reflexivas, vivenciales y problematizadoras, así como al priorizar el aprendizaje significativo, la participación, el intercambio colectivo y la democratización del espacio escolar,"ejercicios que posibilitan la toma de conciencia sobre los derechos humanos, el ejercicio de la ciudadanía y el reconocimiento de la dignidad humana" (CDHDF, 2011, p. 51).

Una propuesta interesante que incluye el programa se dirige a generar un efecto multiplicador al reconocer la importancia de unir esfuerzos en la promoción de la cultura de paz y derechos humanos en las escuelas, de forma que quienes participan en los talleres repliquen las experiencias en sus espacios y se reconozcan como agentes de cambio y sujetos de derechos en el ámbito de la promoción y construcción de una cultura de paz.

\section{Una sociedad que construye la paz: Los desafíos de la educación para la paz, un cambio en las personas para trascender}

La educación para la paz como proceso pedagógico crea espacios de aprendizaje para desaprender la violencia y vivenciar la paz en las relaciones humanas, lo cual es, según Mayor (citado por Monclús, 2008, p. 12), '"desprogramar' conductas de predominio e intolerancia", que causan la desigualdad, la exclusión, la inequidad, la pobreza, el hambre, la discriminación, el odio, el racismo, la injusticia, entre otras desdichas para el desarrollo del ser humano. Posibilita espacios no violentos basados en el diálogo, la comunicación asertiva, la aceptación de las diferencias, el reconocimiento de las otras personas, la cooperación, la resolución pacífica de conflictos, para que germine la cultura de paz. 
doi: http://dx.doi.org/10.15359/ree.19-2.9

URL: http://www.una.ac.cr/educare

Como proceso político busca transformar las relaciones verticales, desiguales, excluyentes y de dominación en los diferentes espacios sociales para favorecer la justicia social, la paz, la igualdad, la equidad y como educación en valores, fomentan la paz y el respeto por los derechos humanos.

Además, está vinculada con la reducción y prevención de la violencia, violencia que daña la vida, la dignidad del ser humano y que no permite relaciones humanas armoniosas ni la construcción de una cultura de paz.

Educar es una forma de incidir en las personas, en la sociedad y en los factores que provocan la violencia, es impactar de alguna forma con algún sentido e intención, es una manera de intervenir para que las personas se reconozcan como agentes de cambio. Por lo tanto, resulta imprescindible reconocer que la cultura de paz, promovida y en constante construcción por la educación para la paz y los derechos humanos, se fundamenta en la acción social, de forma que no separemos los ideales que nos inspiran y nos dan esperanza de los hechos que conforman la realidad cotidiana, sin separar la subjetividad individual de la realidad.

Este tema, por la importancia para América Latina, admite y requiere otras perspectivas para continuar enriqueciéndose y queda abierto para que nuevas investigaciones y trabajos académicos puedan generar aportes; sin embargo, se plantearán algunas reflexiones en torno al hecho de que a pesar de las violencias, las situaciones sociales, políticas y económicas que afectan la región latinoamericana, existen retos importantes necesarios de enfrentar, esenciales para que las personas se vean así mismas como constructoras de una cultura de paz.

\section{Renovar la esperanza}

En los procesos educativos es necesario fomentar, en lo más profundo de cada persona, la esperanza, la cual se dirige al cambio y a la resistencia de las limitaciones internas, sociales, culturales y políticas. Estamos hablando de una educación para la paz que promueva la esperanza en la transformación del ser humano, en la vivencia de los derechos humanos, en la libertad y en la búsqueda constante de nuevas realidades y de propuestas. Rossato (2005 citado por Bajaj, 2008) plantea la esperanza como optimismo transformador, como resistencia a la violencia estructural en la que cada persona se ve a sí misma como participante clave en el proceso colectivo de cambio social.

La esperanza es una necesidad del ser humano, especialmente en circunstancias adversas como la violencia y las injusticias, porque impulsa a las personas a vivir y hasta"indignarse", como menciona Hessel (2010, p. 3): "Yo os deseo a todos, a cada uno de vosotros, que tengáis vuestro motivo de indignación. Es preciso". Esto no se reduce solo a tener el motivo de indignación, sino a la esperanza de vencerlo; esta se traduce en el compromiso que asumimos en la búsqueda de la justicia, de la libertad y de no ser indiferentes. Bien lo decía Freire (2011, p. 24): "Mi esperanza es necesaria pero no suficiente. Ella sola no gana la lucha, pero sin ella la lucha flaquea y titubea". 
doi: http://dx.doi.org/10.15359/ree.19-2.9

URL: http://www.una.ac.cr/educare

CORREO: educare@una.cr

Educar en la esperanza es educar para pensar y creer que la negación de los derechos humanos, la libertad, la justicia y la paz requieren una resistencia de todos los sectores, las personas y la sociedad. La esperanza mueve a las personas a seguir caminando, a negarse a aceptar la realidad como es -violenta, excluyente, desigual-y a negarse a vivir en la desesperanza de la resignación y la indiferencia. Reconoce que las situaciones sociales y las instituciones no se transforman por sí solas, se requiere de personas que lo hagan, que moldeen los procesos sociales, políticos y las relaciones humanas; pues son las personas mismas quienes crean, recrean y construyen la cultura, las instituciones, la política; son quienes toman las decisiones: es en estas personas que radica la esperanza de la transformación.

Sin esperanza, la persona no tendría un sentido de lucha de cambio; se quedaría en la desesperanza, aquella que promueve los brazos caídos, la inmovilidad, la indiferencia, el no futuro promisorio, la apatía y la resignación por las realidades injustas, desiguales, inequitativas y opresivas. La desesperanza invita a pensar que la realidad es así y así se debe aceptar, pero la esperanza es aquella que nos dirige a pensar que no es una realidad determinista, y que el mañana empieza a transformarse desde hoy, como un desafío que debemos enfrentar con la práctica para "volverse historia concreta" (Freire, 2011, p. 25).

\section{Reconocer la autonomía}

La educación para la paz y los derechos humanos que se orienta a la construcción de una cultura de paz, necesariamente, debe estar dirigida al reconocimiento de la autonomía del ser humano. Una autonomía que le permita tomar decisiones, opinar, ser crítico, empoderarse, reconocerse asimismo como sujeto de derechos con dignidad humana, en una realidad social que le puede hacer creer lo contrario. Pero a la vez, un sujeto que se reconozca en un proceso de autoconstrucción constante en las interrelaciones con las otras personas.

Esta se vincula con la autorrealización del ser humano y con la autoafirmación, por lo cual busca gozar y deshacerse de aquello que le impide su disfrute y le interrumpe su proyecto de vida; proyecto que en la autonomía se construye reconociendo la dignidad propia y la de los otros individuos, que, en definitiva, se construye en conjunto.

La autonomía posibilita que la persona reafirme sus capacidades de actuación frente a la violencia, la indiferencia, la injusticia, la violación de derechos, lo que conlleva a asumir la responsabilidad personal ante las situaciones sociales que aquejan a los grupos y a los individuos; esto es, ir contra la corriente, contra el conformismo y contra la obediencia ciega impuesta por el sistema, el poder autoritario y el neoliberalismo. La autonomía va a ir generando capacidades de lucha, de acción y de liberación ante las opresiones violentas y excluyentes. 
doi: http://dx.doi.org/10.15359/ree.19-2.9

URL: http://www.una.ac.cr/educare

CORREO: educare@una.cr

\section{La construcción del sujeto solidario}

Educar para la solidaridad es para construir un sujeto solidario. La solidaridad implica reconocerse en la otra persona, no como quien es diferente, sino con quien se va autoconstruyendo, al reconocer que la autoconstrucción es conjunta en un entramado social. Al solidarizarse con la otra persona, se reconocen los derechos propios y ajenos y así se lucha contra quienes restringen y violan esos derechos.

La solidaridad humana lleva a la persona a identificarse con las necesidades, los sufrimientos, las carencias, los logros y las luchas que surgen en las vidas de las personas y a identificarse en la parte socioafectiva con las demás, con el objetivo de aumentar la calidad de vida y la vivencia y restitución de los derechos humanos. Lleva consigo el aprecio, el respeto y el reconocimiento de la otra persona (no necesariamente concebida como diferente), la compasión y la ternura, la capacidad de asombro ante las injusticias y ante los logros de la vida misma, la búsqueda de la justicia y la paz social, la necesidad de transformar la realidad hacia un hoy y mañana más prometedor por la vida y la alegría.

Sin embargo, la solidaridad no se remite a una mera identificación con las necesidades o las aspiraciones, sino a un compromiso y una práctica de acciones solidarias con las necesidades y las aspiraciones de las demás personas, para transformar realidades injustas, individualistas, de menosprecio, violentas, excluyentes, discriminadoras y transgresoras de los derechos humanos, es un compromiso hacia el cambio en el que se fundamenta una cultura de paz.

La solidaridad es un sentimiento, un sueño, una responsabilidad y una acción importante para la cohesión social, para la humanización de la persona, para la sensibilización y la apertura a una nueva forma de vida que afecta a los otros seres humanos; coexiste con el principio de cooperación, es un ejercicio de corresponsabilidad para mejorar la vida y las relaciones humanas; es, posiblemente, lograr una visión de comunidad, no limitada, sino para crear espacios de coexistencia y nuevas formas de mirarnos y comprendernos mutuamente, sin necesidad de ser iguales.

\section{Pensarnos en la ternura}

Educar para la ternura se relaciona con pensarnos en la ternura, como vivas manifestaciones de la afectividad que se refleja en las relaciones interpersonales basadas en el aprecio, el afecto mutuo y la comprensión del otro individuo. Es reconocer la vivencia de la paz y los derechos humanos en las manifestaciones de lo que somos (creencias, visiones, actividades, principios), entre todos los miembros de la sociedad, en las relaciones humanas cotidianas. 
doi: http://dx.doi.org/10.15359/ree.19-2.9

URL: http://www.una.ac.cr/educare

CORREO: educare@una.cr

Es necesario dejar de lado cualquier forma de incapacidad que nos limite a pensarnos como seres capaces de amar, comprender, expresar buenos sentimientos y emociones, perdonar, crear, compartir, creer, soñar y sentir. Ante esto, la educación para la paz tiene un papel fundamental que se orienta a recuperar

... el alma sensible, la presencia, valoración y expresión de las emociones, los sentimientos y la ternura en todos los espacios y momentos en que el ser humano intenta construirse digna y trascendentemente, todos los días, en una cultura de paz y autentica convivencia y respeto". (Maya, 2003, p. 66)

\section{Construirnos para la vida}

Educar para la vida es educar para el reconocimiento de nuestra dignidad como personas, es "nuestra" dignidad porque yo comprendo mi dignidad en tanto acepto y respeto la dignidad de otras personas, porque nos construimos juntos, en las relaciones sociales, en la comprensión, la aceptación mutua y en el aprecio mutuo.

Construirnos para la vida es construir una cultura de paz, para el aprecio y el respeto; reconocer los derechos propios, a la vez que reconozco el de otras personas; lucho para la vida, al tiempo que lucho por mis derechos y los de otras personas; lucho por la libertad, la paz y la justicia. De acuerdo con Maturana (2007, p. 69): "Nosotros creamos el mundo que vivimos a medida que lo vivimos, y hacemos esto momento a momento» según como estamos en ese momento ..."', es una producción constante y diaria, la cuestión es que si vivimos los derechos humanos, la paz, la libertad y el respeto mutuo hay una existencia efectiva de estos; de lo contrario, no.

\section{Conclusiones}

En la región latinoamericana la violencia a alcanzado a grupos que han sido más vulnerabilizados como las niñez, las mujeres y la juventud. Las manifestaciones de la violencia están marcadas por la desigualdad, la exclusión y la falta de oportunidades desde el nivel micro hasta el macro en la sociedad.

Las personas que forman parte de estos grupos ven sus derechos humanos completamente vulnerados cada vez que sufren violencia y se ven introducidos en círculos de violencia, muchas veces interminables.

Las diversas manifestaciones de la violencia se enmarcan en elementos estructurales que privan a las personas de condiciones mínimas y adecuadas para cubrir sus necesidades básicas humanas y tener calidad de vida, tales como la pobreza, la desigualdad y la exclusión. 
doi: http://dx.doi.org/10.15359/ree.19-2.9

URL: http://www.una.ac.cr/educare

Asimismo, se manifiesta de una forma más abierta, por medio de acciones contra la integridad física que también daña a las persona en todo su ser. También, en aspectos culturales como las relaciones de poder verticales, la subordinación, los estereotipos y las normas que justifican y refuerzan la violencia.

La construcción de una cultura de paz es fundamental para erradicar, disminuir, prevenir y desaprender estas formas de violencia. Esta se va construyendo cada día en torno a la realidad individual y social; en este devenir, es trascendental la educación para la paz como un proceso que permite transformar las personas y las realidades, para que cada quien asuma la paz como una práctica en sus relaciones cotidianas.

Esta forma de educación abarca diversos espacios no violentos en los cuales priman el respeto y reconocimiento de la dignidad humana; es, además, un proceso político, que busca transformar el ejercicio del poder para tener relaciones más igualitarias, solidarias y equitativas.

Así, se ha planteado que la educación para la paz puede incidir en la prevención y disminución de la violencia que afecta determinados grupos, si se logra una transformación en las personas que viven en esa sociedad; para esto, se consideran cinco elementos que se relacionan con la construcción de una cultura de paz: la esperanza, la autonomía, la solidaridad, la ternura y la vida.

Cada persona necesita creer que hay esperanza, para sí misma y para quienes le rodean, no es una esperanza utópica sino aquella que se vincula con la acción, con la resistencia a la opresión y a la injusticia, una esperanza que vislumbra un mejor futuro.

El reconocimiento de la autonomía le permite a cada persona reconocer su dignidad, ejercer sus libertades y reafirmarse en la sociedad en tanto consolida sus capacidades de crítica, lucha y liberación ante todas aquellas acciones que violentan los derechos humanos.

La solidaridad implica una persona solidaria que se comprometa con un proceso de construcción común de la paz, de reconocimiento mutuo de los derechos humanos y aprecio a la dignidad humana. Esto conlleva a que se vea la solidaridad más que como una aspiración lejana, como una aspiración que se logra cada día en la convivencia armoniosa y la comprensión, con un espíritu de responsabilidad.

La ternura es otro elemento esencial, debido a que su búsqueda y su expresión permiten vivir y extender la paz en un entorno de amor, sentimientos positivos y sensibilidad ante las realidades propias y ajenas.

Finalmente, es importante considerar que la educación para la paz educa para la vida, esto es, para vivir en comunidad, en la comprensión, en la búsqueda de mejores oportunidades, de una mejor calidad de vida y de una paz en constante construcción. 
doi: http://dx.doi.org/10.15359/ree.19-2.9

URL: http://www.una.ac.cr/educare

CORREO: educare@una.cr

\section{Referencias}

Asamblea General de Naciones Unidas. (1999). Declaración y programa de acción sobre una cultura de paz. A/RES/53/243. Recuperado de http://www.unesco.org/cpp/sp/ proyectos/suncofp.pdf

Aguilera, B., Cascón, P. y Bastida, A. (2000). Educar para la paz: Una propuesta posible (3a ed.). Madrid: Los libros de la Catarata.

Bajaj, M. (Ed.). (2008). Encyclopedia of Peace Education [Enciclopedia de Paz]. Columbia University.

Beltrán, M. (Mayo-agosto, 2007). La importancia de la educación en los derechos humanos. DEHUIDELA, 15, 37-48. Recuperado de http://www.corteidh.or.cr/tablas/r24457.pdf

Comisión de Derechos Humanos del Distrito Federal (CDHDF). (Septiembre, 2011). Escuela de formación, una alternativa a la violencia en la comunidad educativa. dfensor. Revista de Derechos Humanos, 9, 50-52. Recuperado de http://dfensor.cdhdf.org.mx/ DFensor 09 2011.pdf

Declaración de Luarca (Asturias) sobre el derecho humano a la paz. (2008). Revista de Paz y Conflictos, 1, 109-119. Recuperado de http://www.ugr.es/ revpaz/numeros/rpc $\underline{\text { n1 } 2008 \text { completo.pdf }}$

Freire, P. (2005). Pedagogía del oprimido (2ª ed.). México: Siglo XXI.

Freire, P. (2011). Pedagogía de la esperanza: Un reencuentro con la pedagogía del oprimido ( $3^{\mathrm{a}}$ reimp.). Buenos Aires: Siglo XXI.

Gallardo, H. (Septiembre, 2011). Pensamiento crítico y sujetos colectivos en América Latina. Encuentro "Pensamiento Crítico, Sujetos Colectivos y Universidad", Universidad de la República, Montevideo, Uruguay. Recuperado de http://heliogallardo-americalatina.info/index. php?option=com content\&view=article\&id=277\&catid=11:conversaciones\&ltemid=106

Galtung, J. (2003). Paz por medios pacíficos. Paz y conflicto, desarrollo y civilización (Colección Red Gernika). Bilbao: Bakeaz.

Geneva Declaration on Armed Violence and Development. (2011). Global Burden of Armed Violence 2011 [Carga global de la violencia armada 2011] (Cap. 4). Cambridge: Cambridge University Press Recuperado de http://www.genevadeclaration.org/measurability/globalburden-of-armed-violence/global-burden-of-armed-violence-2011.html

Hessel, S. (2010). Indígnate. Barcelona: Destino. Recuperado de https://coyunturapolitica.files. wordpress.com/2011/05/indignate-sthepane-hessel.pdf 
doi: http://dx.doi.org/10.15359/ree.19-2.9

URL: http://www.una.ac.cr/educare

Jares, X. (1999). Educación para la paz. Su teoría y su práctica. Madrid: Editorial Popular.

Jiménez, F. (2011). Racionalidad pacífica. Una introducción a los estudios para la paz. Madrid: Dykinson.

Magendzo, A. (2008). Pensamiento e ideas-fuerza de la educación en derechos humanos en Iberoamérica. Santiago: UNESCO, OEI. Recuperado de https://docs.google.com/file/d/ 0B54WotxOwtQYNTI5YzZiOWYtZTNjOSO0N2Y0LTImMTktMmE4ODkxOWFjMWVm/ edit?pli=1\&hl=en

Maturana, H. (2007). Transformación en la convivencia. Santiago: Lom Ediciones.

Maya, A. (2003). Conceptos básicos para una pedagogía de la ternura. Bogotá: Ecoe.

Monclús, A. (2008). La educación para la paz en una sociedad globalizada. En A. Monclús y C. Saban (Coords.), Educación para la paz. Enfoque actual y propuestas didácticas (Cap. 1, pp. 17-44). Barcelona: Ediciones CEAC.

Monclús, A. y Sabán, C. (1999). La educación para la paz en un mundo globalizado. En A. Monclús y C. Sabán (Coords.), Educación para la paz (Cap. 4, pp. 71-108). Madrid: Editorial Síntesis.

Muñoz, F. A. (2004). La paz. En F. Muñoz y B. Molina (Eds.), Manual de paz y conflictos (pp. 19-41). España:Universidad de Granada. Recuperado de http://www.ugr.es/ eirene/publicaciones/ eirene manual.html

Oficina Internacional del trabajo (OIT). (2010). Intensificar la lucha contra el trabajo infantil. Recuperado de http://www.ilo.org/wcmsp5/groups/public/---ed norm/---relconf/ documents/meetingdocument/wcms 136697.pdf

Organización Iberoamericana de Juventud (OIJ). (2011). Políticas de juventud en Centroamérica. Construyendo un paradigma para el desarrollo social. Recuperado de http://www.oij.org/ file upload/publicationsltems/document/20111212144942 22.pdf

Pinheiro, M. T. (30 de junio al 3 de julio, 2006). El juego cooperativo y la cultura de la paz en la educación infantil. V Congreso Internacional de Actividades Físicas Cooperativas. Oleiros, Coruña:. Recuperado de http://www.labrinjo.ufc.br/phocadownload/artigo\%20 -\%200\%20brincar\%20cooperativo $\% 20$ e $\% 20$ a $\% 20$ cultura $\% 20$ da $\% 20$ paz $\% 20$ na $\% 20$ educaao\%20infantil\%20en\%20espaol.pdf

Pinheiro, P. S. (2006). Informe mundial de la violencia contra los niños y las niñas. Recuperado de http://www.unicef.org/lac/Informe Mundial Sobre Violencia 1(1).pdf

UNESCO. (1999). Manifiesto 2000 para una cultura de paz y no violencia. Recuperado de http:// www3.unesco.org/manifesto2000/sp/sp manifeste.htm 
doi: http://dx.doi.org/10.15359/ree.19-2.9

URL: http://www.una.ac.cr/educare

CORREO: educare@una.cr

UNICEF. (2006). La violencia contra niños, niñas y adolescentes. Informe de América Latina en el marco del estudio mundial de las Naciones Unidas. 2006. Recuperado de http://www.unicef. org/lac/Estudio violencia\%281\%29.pdf

UNICEF. (2011). Violencia escolar en América Latina y el Caribe. Superficie y fondo. Recuperado de http://www.unicef.org/lac/violencia escolar OK.pdf

Comisión Económica para América Latina y El caribe (CEPAL) y Naciones Unidas. (2008). Panorama social de América Latina 2008. Santiago, Chile: Naciones Unidas. Recuperado de http://www.cepal.org/es/publicaciones/panorama-social-de-america-latina-2008

\section{(O) Cómo citar este artículo en APA:}

Cerdas-Agüero, E. (Mayo-agosto, 2015). Desafíos de la educación para la paz hacia la construcción de una cultura de paz. Revista Electrónica Educare, 19(2), 135-154. doi: http://dx.doi.org/10.15359/ree.19-2.9

Nota: Para citar este artículo en otros sistemas puede consultar el hipervínculo "Como citar el artículo" en la barra derecha de nuestro sitio web: http://www.revistas.una.ac.cr/index.php/EDUCARE/index 